\title{
Impact of embryo transfer on dairy cattle improvement in the United States
}

\author{
H.D. NORMAN, R.L. POWELL and F.N. DICKINSON \\ Animal Improvement Programs Laboratory, United States Department of Agriculture, \\ Beltsville, Maryland 20705, U.S.A.
}

Embryo transfer for dairy cattle in the United States has been used most extensively by Holstein-Friesian breeders, with a rapid increase since 1975. Brown Swiss, Jersey, and Red and White breeders also have reported use of embryo transfer recently. Estimated transmitting abilities for embryo donors are above average, although not outstanding, as are estimated transmitting abilities for sires of these donors. However, donors were mated to bulls with higher genetic merit. one individual bull sired 18 p. 100 of Holstein-Friesian offspring from embryo transfer ; five bulls sired 37 p. 100 . Donors were less related, but five bulls sired 28 p. 100 of the donors.

\section{The utilization of selection after 100-days lactation in forming a high productive Red and White herd}

\author{
J. ROMER, Hanna CZAJA, P. CIELAR \\ Institute of Animal Husbandry, Cracov, Poland
}

The investigations of milk productivity of 217 Red and White cows in first 100 days of lactation were carried out. The cows were purchased as pregnant heifers on the market. On the basis of 100 days lactation yield all cows were divided into 3 groups : $\mathrm{N}-$ a control group (the cows chosen at random), $\mathrm{S}$ - cows with milk yield above average and $\mathrm{B}$ - the cows with milk yield below average. The milk yield during Ist, 2nd and 3rd lactation of $\mathrm{S}$ and $\mathrm{N}$ groups was tested. The cows of group $\mathrm{S}$ exceeded group $\mathrm{N}$ by $464 \mathrm{~kg}$ of milk production in 1st lactation, $257 \mathrm{~kg}$ in 2nd and $543 \mathrm{~kg}$ in $3 \mathrm{rd}$. Average milk yield of $S$ group was : $3463 \mathrm{~kg}, 3963 \mathrm{~kg}$ and $4338 \mathrm{~kg}$ in 1st, 2nd and 3 rd respectively.

\section{Correlations among traits in dual purpose cattle}

\author{
W. SCHLOTE and J. MUNKS \\ Institute of Animal Production, Technical University of Berlin, \\ Lentzeallee 75, D-1000 Berlin 33, Germany
}

Different data sets of the Simmental cattle population in Baden-Würtemberg state were used to estimate genetic correlations among different traits. Most values were in the order of other estimates known from literature. However, relatively high positive correlations were observed for 112-day weight and milk and fat yield, considerable negative correlations between non-return rate and all production traits and small positive (for breeding purposes negative) values between calving performance and all production traits. Despite of relatively high standard errors the estimates give some indication about the genetic relationships. 